\title{
HERANÇA DA TOLERÂNCIA À TOXIDEZ DE ALUMÍNIO EM ARROZ COM BASE EM ANÁLISE DIALÉLICA ${ }^{1}$
}

\author{
REINALDO DE PAULA FERREIRA², COSME DAMIÃO CRUZ³, \\ CARLOS SIGUEYUKI SEDIYAMA ${ }^{3}$ e BEATRIZ SILVEIRA PINHEIRO ${ }^{4}$
}

\begin{abstract}
RESUMO - Objetivando estudar a herança da tolerância à toxidez de alumínio (Al) em arroz (Oryza sativa L.) avaliaram-se três genótipos tolerantes (Guarani, Guaporé e IAC 25) e três sensíveis (CNA 5600, CNA 5615 e IAC 899) à toxidez de $\mathrm{Al}$ e seus respectivos cruzamentos $\mathrm{F}_{1}$ em um sistema de cruzamento dialélico, desconsiderando os recíprocos, na concentração de $20 \mathrm{mg} / \mathrm{L}$ de $\mathrm{Al}$, em solução nutritiva. Os resultados encontrados evidenciaram que a herança da tolerância à toxidez de $\mathrm{Al}$ em arroz é oligogênica, com os alelos dominantes determinando essa tolerância. Os progenitores Guarani, Guaporé e IAC 25 apresentaram maior concentração de alelos dominantes, e CNA 5600, CNA 5615 e IAC 899 maior número de alelos recessivos.
\end{abstract}

Termos para indexação: Oryza sativa, cruzamentos, solução nutritiva.

\section{INHERITANCE OF TOXICITY ALUMINUM TOLERANCE ON RICE BASED ON DIALLELIC ANALYSIS}

\begin{abstract}
Three tolerant (Guarani, Guaporé e IAC 25) and three sensitive (CNA 5600, CNA 5615 e IAC 899) genotypes of rice (Oryza sativa L.) and their respective $\mathrm{F}_{1}$ crosses, obtained in a diallel cross system not accounting the reciprocal crosses, were evaluated to study the inheritance of toxicity aluminum (Al) tolerance. The $\mathrm{Al}$ concentration in nutritive solution was $20 \mathrm{mg} / \mathrm{L}$. The results showed that the inheritance is oligogenic with the tolerance determined by the dominant alleles. The parents Guarani, Guaporé and IAC 25 showed greater dominant allele concentration and CNA 5600, CNA 5615 and IAC 899 more recessive alleles.
\end{abstract}

Index terms: Oryza sativa, crosses, nutritive solution.

\section{INTRODUÇÃO}

A toxidez de Al é um fator limitante do crescimento dos cereais, em particular da cultura de arroz de sequeiro (Martinez, 1977).

$\mathrm{O}$ principal efeito de níveis tóxicos de $\mathrm{Al}$ é o menor crescimento radicular de plantas sensíveis, já que este elemento afeta o alongamento e a divisão celular (Clarkson, 1969). Nessas condições,

\footnotetext{
${ }^{1}$ Aceito para publicação em 7 de outubro de 1998.

${ }^{2}$ Eng. Agr., Dr., Embrapa-Centro Nacional de Pesquisa de Gado de Leite (CNPGL), Rua Eugênio do Nascimento, 610, Dom Bosco, CEP 36038-330 Juiz de Fora, MG. E-mail: ferreira@cnpgl.embrapa.br

${ }^{3}$ Eng. Agr., Dr., Prof. Titular, Universidade Federal de Viçosa, CEP 36571-000 Viçosa, MG.

${ }^{4}$ Eng ${ }^{\mathrm{a}}$ Agr ${ }^{\mathrm{a}}$, Dr ${ }^{\mathrm{a}}$, Embrapa-Centro Nacional de Pesquisa de Arroz e Feijão (CNPAF), Caixa Postal 179, CEP 74001-970 Goiânia, GO.
}

as plantas não conseguem obter adequadamente água e nutrientes do subsolo, em face do enraizamento superficial, tornando-se menos produtivas e mais susceptíveis à seca (Lance \& Pearson, 1969).

Uma alternativa para melhorar a fertilidade dos solos é a incorporação profunda de corretivos e fertilizantes. Entretanto, as técnicas atualmente disponíveis para tal fim são consideradas impraticáveis, quer por não ser conhecida uma metodologia que permita controlar adequadamente o Al permutável na parte subsuperficial dos solos, quer como conseqüência de custos dos corretivos e de sua aplicação, quer pela grande extensão de áreas formadas por solos apresentando acidez nociva em grau considerável (Olmos \& Camargo, 1976).

A opção mais promissora para contornar o problema é a exploração do potencial genético das cultivares, pois sabe-se que existem diferenças entre as espécies e entre as variedades dentro da mesma 
espécie, quanto à tolerância à toxidez de $\mathrm{Al}$ (Foy, 1974; Ferreira, 1995).

O objetivo deste trabalho foi estudar a herança da tolerância à toxidez de $\mathrm{Al}$ em arroz.

\section{MATERIAL E MÉTODOS}

Neste experimento, foram avaliados três genótipos tolerantes (Guarani, Guaporé e IAC 25) e três sensíveis (CNA 5600, CNA 5615 e IAC 899) à toxidez de Al e seus respectivos $F_{1 s}$ em um sistema de cruzamento dialélico, desconsiderando os recíprocos. O delineamento experimental adotado foi o de blocos casualizados, com três repetições, utilizando-se 13 plantas por tratamento.

Inicialmente, as sementes, após serem tratadas com Vitavax e Thiram, foram colocadas para germinar em rolos de papel especial para germinação, umedecidas com água destilada, permanecendo no germinador durante
70 horas, à temperatura de $25^{\circ} \mathrm{C}$ e umidade relativa de $100 \%$, com a radícula alcançando, aproximadamente, $3 \mathrm{~cm}$.

Posteriormente, após medir-se o comprimento inicial da raiz, plântulas fenotipicamente uniformes foram transferidas para caixas de plástico com $37 \mathrm{~cm}$ de comprimento, $30 \mathrm{~cm}$ de largura e $14 \mathrm{~cm}$ de altura. Cada caixa continha 15 litros de solução nutritiva (Tabela 1), cuja composição química é uma modificação daquela proposta por Furlani \& Hanna (1984). Utilizou-se a concentração de $20 \mathrm{mg} / \mathrm{L}$ de $\mathrm{Al}$, por ser este nível considerado crítico para estudos genéticos em arroz, por apresentar a melhor discriminação genotípica entre os materiais avaliados, conforme já evidenciado por Ferreira (1995).

Para a sustentação das plântulas no recipiente com solução nutritiva foram empregadas chapas de acrílico perfuradas. Em cada perfuração, acomodou-se uma plântula, cuja radícula alcançou a solução nutritiva.

TABELA 1. Composição da solução-estoque e da solução nutritiva usadas para o cultivo de plantas de arroz em estudos de estresse de alumínio.

\begin{tabular}{|c|c|c|c|c|c|}
\hline \multirow[t]{2}{*}{ Solução } & \multicolumn{2}{|c|}{ Solução-estoque } & \multirow{2}{*}{$\begin{array}{c}\text { Volume }(\mathrm{mL}) \mathrm{da} \\
\text { solução-estoque/L } \\
\text { da solução nutritiva }\end{array}$} & \multicolumn{2}{|c|}{ Solução nutritiva } \\
\hline & Componente & Concentração $(\mathrm{g} / \mathrm{L})$ & & Componente & Concentração $(\mathrm{mg} / \mathrm{L})$ \\
\hline 1 & $\mathrm{Mg}\left(\mathrm{NO}_{3}\right)_{2} \cdot 6 \mathrm{H}_{2} \mathrm{O}$ & 142,4 & 0,28 & $\mathrm{Ca}$ & 30,0 \\
\hline 2 & $\mathrm{KH}_{2} \mathrm{PO}_{4}$ & 17,6 & 0,05 & $\mathrm{~K}$ & 18,0 \\
\hline \multirow[t]{2}{*}{3} & $\mathrm{Ca}\left(\mathrm{NO}_{3}\right)_{2} \cdot 4 \mathrm{H}_{2} \mathrm{O}$ & 270,0 & 0,66 & $\mathrm{Mg}$ & 3,8 \\
\hline & $\mathrm{NH}_{4} \mathrm{NO}_{3}$ & 33,8 & & $\mathrm{NO}_{3}^{-}$ & 32,0 \\
\hline \multirow[t]{2}{*}{4} & $\mathrm{FeSO}_{4} \cdot 7 \mathrm{H}_{2} 0$ & 24,9 & 0,33 & $\mathrm{NH}_{4}^{+}$ & 4,0 \\
\hline & $\mathrm{Na}_{2}$ EDTA & 29,6 & & $\mathrm{P}$ & 0,2 \\
\hline \multirow[t]{3}{*}{5} & $\mathrm{KCl}$ & 18,6 & 0,46 & B & 0,11 \\
\hline & $\mathrm{KNO}_{3}$ & 24,6 & & $\mathrm{Fe}$ & 1,65 \\
\hline & $\mathrm{K}_{2} \mathrm{SO}_{4}$ & 44,0 & & $\mathrm{Mn}$ & 0,21 \\
\hline \multirow[t]{5}{*}{6} & $\mathrm{MnCl}_{2} \cdot 4 \mathrm{H}_{2} \mathrm{O}$ & 2,34 & 0,33 & Mo & 0,03 \\
\hline & $\mathrm{H}_{3} \mathrm{BO}_{3}$ & 2,04 & & $\mathrm{Zn}$ & 0,10 \\
\hline & $\mathrm{CuSO}_{4} \cdot 5 \mathrm{H}_{2} \mathrm{O}$ & 0,20 & & $\mathrm{Cu}$ & 0,01 \\
\hline & $\mathrm{ZnSO}_{4} \cdot 7 \mathrm{H}_{2} \mathrm{O}$ & 1,41 & & $\mathrm{Al}$ & 20,0 \\
\hline & $\mathrm{Na}_{2} \mathrm{MoO}_{4} \cdot 2 \mathrm{H}_{2} \mathrm{O}$ & 0,26 & & & \\
\hline 7 & $\mathrm{AlCl}_{3} \cdot 6 \mathrm{H}_{2} \mathrm{O}$ & 89,48 & 2,00 & & \\
\hline
\end{tabular}


Durante o período de crescimento, que se prolongou durante 10 dias, após a transferência das plântulas para as caixas, corrigiu-se diariamente o $\mathrm{pH}$ da solução nutritiva para 4,0, com adição de $\mathrm{HCl}$ ou $\mathrm{NaOH} 0,5 \mathrm{M}$. Nesse período, a temperatura diurna na câmara de crescimento foi de $27 \pm 1^{\circ} \mathrm{C}$ e a noturna de $24 \pm 1^{\circ} \mathrm{C}$, enquanto a umidade relativa diurna foi próxima de $80 \%$ e a noturna de $100 \%$. O fotoperíodo foi de 12 horas, com uma densidade de fluxo de fótons de $800 \mathrm{mE} / \mathrm{m}^{2} /$ segundo na altura da copa da planta, fornecido por lâmpadas fluorescentes e incandescentes.

Após o período de 10 dias, as plântulas foram medidas, e o sistema radicular e a parte aérea foram colocados separadamente em sacos de papel e submetidos à secagem em estufa com ventilação forçada, a $75^{\circ} \mathrm{C}$, durante 48 horas.

Determinaram-se os seguintes caracteres: comprimento da raiz, medido do coleto da planta até à extremidade da raiz; matéria seca da raiz; matéria seca da parte aérea; matéria seca total - soma dos pesos da matéria seca da parte aérea e da raiz; e altura da planta.

Para o estudo da herança da tolerância à toxidez de $\mathrm{Al}$, utilizou-se a metodologia de Hayman (1954), avaliando-se o grau médio de dominância, a distribuição dos alelos entre os progenitores, o limite teórico de seleção, a relação entre alelos favoráveis e dominância, o número de genes que exibem dominância, a proporção entre genes dominantes e recessivos, e o coeficiente de determinação genotípico.

\section{RESULTADOS E DISCUSSÃO}

A suficiência do modelo aditivo dominante nos caracteres comprimento da raiz, peso da matéria seca da raiz, da parte aérea e total e altura da planta está apresentada na Tabela 2. O método Hayman (1954) impõe as seguintes restrições: a) progenitores homozigóticos; b) segregação diplóide; c) ausência de efeito materno; d) ausência de alelismo múltiplo; e) genes independentemente distribuídos entre os pais; f) ausência de epistasia.

As quatro primeiras restrições são plenamente satisfeitas em arroz, em que se dispõe de indivíduos diplóides, a homozigoze é alcançada naturalmente e não há registros de efeitos materno e alelismo múltiplo nos diversos caracteres avaliados. A pressuposição de distribuição independente entre os progenitores constitui, na maioria das vezes, a principal causa de falhas na análise dialélica, porém Hayman (1960) considera que, quando se trabalha com pequeno número de progenitores e o modelo genético é fixo, as estimativas dos parâmetros genéticos são pouco comprometidas. Assim, quando ocorre significância do teste do modelo aditivo dominante em arroz, uma conseqüência

TABELA 2. Teste de suficiência do modelo genético dos caracteres comprimento da raiz sem (CR) e com transformação logarítmica (Log CR), peso da matéria seca da raiz (PSR), da parte aérea (PSPA) e total (PST) e altura da planta (AP), segundo a metodologia de Hayman (1954), na concentração de $20 \mathrm{mg} / \mathrm{L}$ de alumínio.

\begin{tabular}{|c|c|c|c|c|c|c|c|}
\hline \multirow[t]{2}{*}{ Carácter } & \multicolumn{3}{|c|}{$\operatorname{Anova}\left(\hat{\mathrm{W}}_{\mathrm{i}}-\hat{\mathrm{V}}_{\mathrm{i}}\right)^{1}$} & \multicolumn{4}{|c|}{ Regressão $W_{i}=1 / 4\left(D-H_{1}\right)+b$ Vi } \\
\hline & $\begin{array}{c}\text { QM } \\
\text { (Linhas) }\end{array}$ & $\begin{array}{c}\text { QM } \\
\text { (Resíduo) }\end{array}$ & $\begin{array}{c}\text { QM } \\
\text { (Regressão) }\end{array}$ & Desvio & $\hat{\mathrm{b}}$ & $\mathrm{t}\left(\mathrm{H}_{0}: \mathrm{b}=1\right)$ & $\mathrm{t}\left(\mathrm{H}_{0}: \mathrm{b}^{\prime}=0\right)$ \\
\hline $\mathrm{CR}$ & $1,0612 * *$ & 0,1650 & 142,3309 & 0,1771 & 1,2077 & $4,8761 * *$ & $-5,7235 * *$ \\
\hline $\log C R$ & $1,2176.10^{-3 \mathrm{~ns}}$ & $0,3675 \cdot 10^{-3}$ & $672,3971.10^{-3}$ & $0,3702.10^{-3}$ & 1,0832 & $1,9837^{\text {ns }}$ & $2,1055^{\mathrm{ns}}$ \\
\hline PSR & $3,9553.10^{-3} * *$ & $0,1361.10^{-3}$ & $2.5270 .10^{-3}$ & $0,6559.10^{-3}$ & 0,3235 & $-4,1038 * *$ & $1,3971^{\mathrm{ns}}$ \\
\hline PSPA & $1.004 .9253 .10^{-3} * *$ & $24,9860 \cdot 10^{-3}$ & $1.399 .6362 .10^{-3}$ & $65.6603 .10^{-3}$ & 0,3627 & $-8,1105^{* *}$ & $4,8977^{* *}$ \\
\hline PST & $2.400,3205.10^{-3} * *$ & $51,7148.10^{-3}$ & $1.851,7139.10^{-3}$ & $153,2569.10^{-3}$ & 0,2988 & $-8,1576^{* *}$ & $4,6098 * *$ \\
\hline $\mathrm{AP}$ & $8,8210^{\mathrm{ns}}$ & 5,2889 & 990,6230 & 13,6850 & 1,0006 & $0,0053^{\mathrm{ns}}$ & $-0,9462^{\mathrm{ns}}$ \\
\hline
\end{tabular}

1 Anova com os valores de $\mathrm{W}_{\mathrm{i}}-\mathrm{V}_{\mathrm{i}}$ em cada bloco; quando $\mathrm{F}$ não é significativo, aceita-se a hipótese de homogeneidade de $\mathrm{W}_{\mathrm{i}}-\mathrm{V}_{\mathrm{i}}$.

${ }^{* *}$ Significativo a $1 \%$ de probabilidade.

ns Não-significativo. 
imediata mais provável é a ocorrência de epistasia no caráter em estudo.

Quanto aos caracteres comprimento da raiz, pesos da matéria seca da raiz, da parte aérea e total, houve significância do teste de suficiência do modelo aditivo dominante, o que evidencia a presença de epistasia (Tabela 2). Para essas características, portanto, o modelo não se aplica. Entretanto, ao logaritmizar os dados associados ao caráter comprimento da raiz, o modelo aditivo dominante tornou-se suficiente, possibilitando, assim, obter as estimativas dos parâmetros genéticos relativos a esta característica. A regressão de $\hat{\mathrm{W}}_{\mathrm{i}}$ (co-variância obtida entre progenitores e a i-ésima linha da tabela dialélica), em função de $\hat{\mathrm{V}}_{\mathrm{i}}$ (variância obtida na i-ésima linha da tabela dialélica), referente ao caráter altura da planta, mostrou que $\mathrm{b}=1,0006$ não diferiu de 1 , a $1 \%$ de probabilidade, comprovando, assim, que o modelo aditivo dominante é adequado neste caso, não havendo, portanto, evidência de epistasia.

Mather \& Jinks (1984) recomendam a mudança de escala quando há insucesso no ajuste do modelo aditivo dominante aos dados. A justificativa para o uso de uma escala transformada não é teórica, mas empírica, removendo ou reduzindo a interdependência dos efeitos dos genes, permitindo, assim, o uso do modelo aditivo dominante com análise mais simples e levando a previsões mais seguras, com a natureza do caráter, sugerindo, muitas vezes, a transformação apropriada.

Pela Tabela 3, observa-se que o caráter comprimento da raiz mostrou alta correlação negativa

TABELA 3. Outros parâmetros estimados no dialelo, pelo método de Hayman (1954), para os caracteres comprimento da raiz sem $(C R)$ e com transformação logarítmica $(\log C R)$ e altura da planta (AP), na concentração de $20 \mathrm{mg} / \mathrm{L}$ de alumínio'.

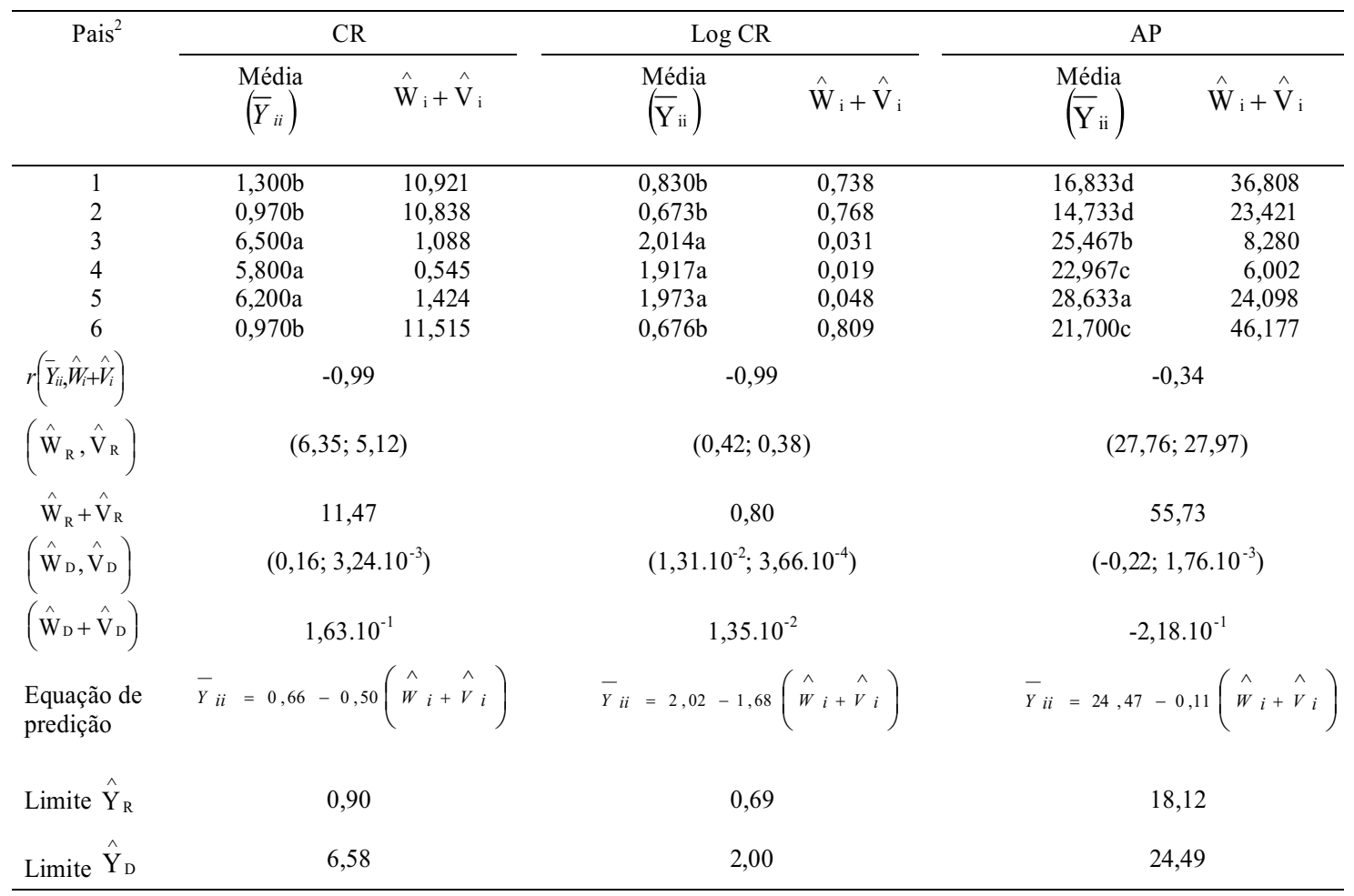

${ }^{1}$ As médias, seguidas pela mesma letra na vertical, não diferem significativamente entre si, pelo teste de Tukey, a $5 \%$ de probabilidade.

2 1: CNA 5600; 2: CNA 5615; 3: Guarani; 4: Guaporé; 5: IAC 25; 6: IAC 899. 
entre $\hat{\mathrm{w}}_{\mathrm{i}}+\hat{\mathrm{v}}_{\mathrm{i}}$ e $\overline{\mathrm{y}}_{\mathrm{ii}}$, de $-0,99$, mostrando, dessa forma, que os alelos dominantes são, em sua maioria, responsáveis pelo acréscimo do comprimento da raiz. Os progenitores Guarani, Guaporé e IAC 25 apresentaram maior concentração de alelos dominantes e CNA 5600, CNA 5615 e IAC 899, maior número de genes recessivos (Fig. 1).

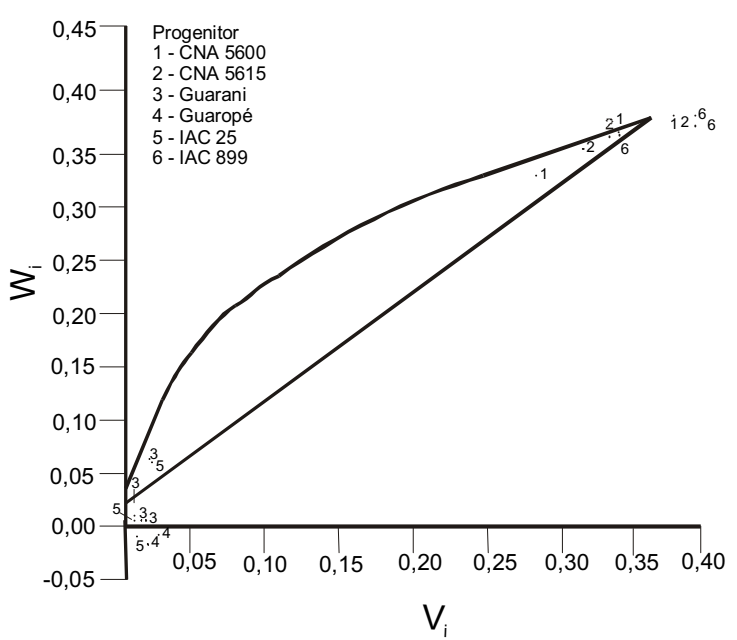

FIG.1. Regressão de $W_{i}$ sobre $V_{i}$ para comprimento da raiz, com transformação logarítmica, na concentração de $20 \mathrm{mg} / \mathrm{L}$ de alumínio.
O progenitor de máxima homozigose recessiva deverá apresentar $\hat{\mathrm{W}}_{\mathrm{i}}+\hat{\mathrm{V}}_{\mathrm{i}}=0,80$ e os progenitores CNA 5600, CNA 5615 e IAC 899 estão próximos desse valor. Os progenitores Guarani, Guaporé e IAC 25 possuem elevada concentração de genes dominantes, pois seus valores de $\hat{\mathrm{W}}_{\mathrm{i}}+\hat{\mathrm{V}}_{\mathrm{i}}$ estão próximos de 0,013 , destacando-se a cultivar Guaporé (Tabela 3).

O aumento do comprimento da raiz pode ser conseguido com maior concentração de genes dominantes. O valor máximo do Logarítmo do comprimento da raiz esperado é de 2,00, correspondendo a 7,4 cm, com os progenitores Guarani, Guaporé e IAC 25 estando próximos deste valor (Tabela 3 ).

A Tabela 4 mostra que a estimativa de $\mathrm{D}-\mathrm{H}_{1}$ foi positiva, evidenciando a predominância dos efeitos gênicos aditivos no controle gênico do caráter comprimento da raiz.

A estimativa do grau médio de dominância foi de 0,84 , o que evidencia que nos alelos que atuam no controle gênico do caráter comprimento da raiz, ocorre dominância parcial (Tabela 4). De fato, a reta de regressão intercepta a ordenada acima da origem, concordando com esses resultados (Fig. 1).

A estimativa de simetria próxima de 0,25 indica que os alelos estão distribuídos de maneira simétrica entre os progenitores. Pela relação dominante

TABELA 4. Estimativa dos componentes e parâmetros genéticos do dialelo, em relação ao comprimento da raiz, com transformação logarítmica, na concentração de $20 \mathrm{mg} / \mathrm{L}$ de alumínio.

\begin{tabular}{cclc}
\hline Componente $^{1}$ & $\begin{array}{c}\text { Estimativa } \pm \\
\text { desvio-padrão }\end{array}$ & \multicolumn{1}{c}{ Parâmetro } & Estimativa \\
\hline $\mathrm{E}$ & $0,0064 \pm 0,0080$ & Grau médio de dominância & 0,8424 \\
$\mathrm{D}$ & $0,4624 \pm 0,0188$ & Simetria & 0,2494 \\
$\mathrm{H}_{1}$ & $0,3281 \pm 0,0551$ & Relação dominante/recessivo & 1,1918 \\
$\mathrm{H}_{2}$ & $0,3274 \pm 0,0480$ & Número de genes com dominância & 0,4327 \\
$\mathrm{~h}^{2}$ & $0,1417 \pm 0,0283$ & Herdabilidade restrita & 0,6912 \\
$\mathrm{~F}$ & $0,0682 \pm 0,0452$ & Herdabilidade ampla & 0,9777 \\
$\mathrm{D}-\mathrm{H}_{1}$ & $0,1342 \pm 0,0475$ & Correlação $\left(\overline{\mathrm{Y}}_{\mathrm{ii}}, \hat{\mathrm{W}}_{\mathrm{i}}+\hat{\mathrm{V}}_{\mathrm{i}}\right)$ & $-0,9900$ \\
\hline
\end{tabular}

${ }^{1}$ E: componente de variância ambiental; D: componente de variância associado aos efeitos aditivos; $\mathrm{H}_{1}$ : componente de variância associado aos desvios da dominância; $\mathrm{H}_{2}$ : componente de variância associado aos desvios da dominância; $\mathrm{h}^{2}$ : componente quadrático determinado pela diferença de média entre híbridos e pais; F: componente associado à covariância entre efeitos aditivos e não aditivos. 
recessiva evidencia-se também a distribuição simétrica dos alelos entre os progenitores, havendo, entretanto, ligeira predominância de alelos dominantes (Tabela 4). Distribuição simétrica dos alelos entre os progenitores permite o conhecimento prévio da freqüência alélica da população-base. Quando há simetria, a freqüência de p e q é 0,5 , podendo este fato ser de interesse, uma vez que, normalmente, não se sabe, a princípio, qual alelo é favorável.

A estimativa do número de genes que exibem dominância foi de 0,43 , mostrando, assim, que o caráter comprimento da raiz em arroz, em presença de $20 \mathrm{mg} / \mathrm{L}$ de $\mathrm{Al}$, é governado por poucos genes. Entretanto, a variação contínua observada nos ensaios, é uma forte evidência de ser este caráter quantitativo. A herdabilidade no sentido amplo foi de 0,98 e, no sentido restrito, de 0,69 , evidenciando, mais uma vez, que o efeito gênico aditivo prepondera sobre o efeito devido à dominância para o caráter comprimento da raiz (Tabela 4).

Pela Tabela 3, observa-se que o caráter altura da planta mostrou correlação negativa, porém, de baixa magnitude, entre $\hat{\mathrm{w}}_{\mathrm{i}}+\hat{\mathrm{v}}_{\mathrm{i}}$ e $\overline{\mathrm{y}}_{\mathrm{ii}}(\mathrm{r}=-0,34)$. Assim, não há total evidência de que os alelos que atuam no sentido de aumentar a média deste caráter tendem a ser predominantemente dominantes. Os progenitores Guarani e Guaporé apresentaram maior concentração de alelos dominantes e IAC 899, CNA 5600, CNA 5615 e IAC 25, maior número de genes recessivos (Fig. 2).

O progenitor de máxima homozigose recessiva deverá apresentar $\hat{\mathrm{w}}_{\mathrm{i}}+\hat{\mathrm{v}}_{\mathrm{i}}=55,73$ e o progenitor CNA 5600 foi o que mais se aproximou desse valor. O progenitor de máxima homozigoze dominante deverá apresentar $\hat{\mathrm{w}}_{\mathrm{i}}+\hat{\mathrm{v}}_{\mathrm{i}}=-0,22$ e o progenitor Guaporé, apesar de reter a maior proporção de genes dominantes, apresenta $\hat{\mathrm{w}}_{\mathrm{i}}+\hat{\mathrm{v}}_{\mathrm{i}}=6,00$, o que indica possibilidade de obtenção de linhagens com maior concentração de alelos dominantes nas populações segregantes (Tabela 3).

O aumento da altura da planta pode ser conseguido com maior concentração de genes dominantes. A altura máxima da planta é de $24,49 \mathrm{~cm}$, com o progenitor IAC 25 já ultrapassando este valor, o que indica que não há grandes dificuldades, por meio do melhoramento, de aumentar ainda mais este caráter (Tabela 3). Entretanto, deve-se ressaltar que, normalmente, em arroz, plantas mais altas tendem a acamar.

A Tabela 5 mostra que a estimativa de $\hat{\mathrm{D}}-\hat{\mathrm{H}}_{1}$ apesar de positiva, não supera o respectivo desvio-padrão, evidenciando a predominância tanto dos efeitos gênicos aditivos quanto não-aditivo no controle da altura da planta. A estimativa do grau médio de dominância foi de 0,92 , o que indica que nos alelos que atuam no controle gênico do caráter altura da planta, ocorre dominância parcial. De fato, a reta de regressão intercepta a ordenada acima da origem, o que está de acordo com esses resultados (Fig. 2)

A estimativa de simetria está próxima de 0,25 , mostrando simetria dos genes entre os progenitores. Pela relação dominante/recessivo, evidencia-se também a distribuição simétrica dos alelos entre os progenitores, havendo, entretanto, ligeira predominância de alelos dominantes (Tabela 5).

A estimativa do número de genes que exibem dominância foi de 0,32 , a herdabilidade no sentido amplo foi de 0,92 e, no sentido restrito, de 0,61, evidenciando, mais uma vez, que o efeito gênico aditivo prepondera sobre o efeito devido à dominância para o caráter altura da planta (Tabela 5).

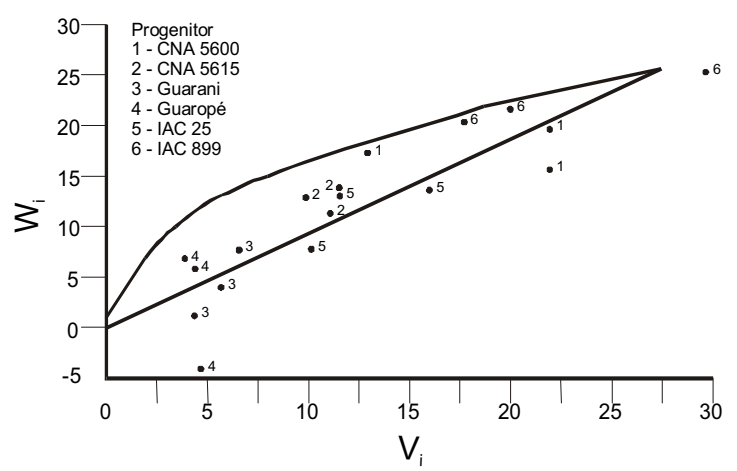

FIG. 2. Regressão de $W_{i}$ sobre $V_{i}$ para altura da planta, na concentração de $20 \mathrm{mg} / \mathrm{L}$ de alumínio. 
TABELA 5. Estimativa dos componentes e parâmetros genéticos do dialelo, em relação à altura da planta, na concentração de $20 \mathrm{mg} / \mathrm{L}$ de alumínio.

\begin{tabular}{cclc}
\hline Componente $^{1}$ & $\begin{array}{c}\text { Estimativa } \pm \text { desvio- } \\
\text { padrão }\end{array}$ & \multicolumn{1}{c}{ Parâmetro } & Estimativa \\
\hline $\mathrm{E}$ & $1,4385 \pm 1,1930$ & Grau médio de dominância & 0,9216 \\
$\mathrm{D}$ & $26,1226 \pm 2,8041$ & Simetria & 0,2434 \\
$\mathrm{H}_{1}$ & $22,1858 \pm 8,2141$ & Relação dominante/recessivo & 1,2511 \\
$\mathrm{H}_{2}$ & $21,6042 \pm 7,1557$ & Número de genes com dominância & 0,3233 \\
$\mathrm{~h}^{2}$ & $6,9838 \pm 4,2152$ & Herdabilidade restrita & 0,6093 \\
$\mathrm{~F}$ & $5,3713 \pm 6,7424$ & Herdabilidade ampla & 0,9178 \\
$\mathrm{D}-\mathrm{H}_{1}$ & $3,9368 \pm 7,0811$ & Correlação $\left(\overline{\mathrm{Y}}_{\mathrm{ii}}, \hat{\mathrm{W}}_{\mathrm{i}}+\hat{\mathrm{V}}_{\mathrm{i}}\right)$ & $-0,3400$ \\
\hline
\end{tabular}

${ }^{1}$ E: componente de variância ambiental; D: componente de variância associado aos efeitos aditivos; $\mathrm{H}_{1}$ : componente de variância associado aos desvios da dominância; $\mathrm{H}_{2}$ : componente de variância associado aos desvios da dominância; $\mathrm{h}^{2}$ : componente quadrático determinado pela diferença de média entre híbridos e pais; F: componente associado à covariância entre efeitos aditivos e não aditivos.

\section{CONCLUSÕES}

1. A herança da tolerância à toxidez de $\mathrm{Al}$ em arroz é oligogênica.

2. Os alelos dominantes determinam essa tolerância.

\section{REFERÊNCIAS}

CLARKSON, D.T. Metabolic aspects of aluminium toxicity and some possible mechanisms for resistance. In: RORISON, I.H. (Ed.). Ecological aspects for the mineral nutrition of plants. Oxford: Blackwell Scientific Pub., 1969. p.381-397.

FERREIRA, R. de P. Análises biométricas da tolerância do arroz (Oryza sativa $L$.) à toxidez de alumínio.

Viçosa, MG: UFV, Impr. Univ., 1995. 123p. Tese de Doutorado.

FOY, C.D. Effects of aluminum on plant growth. In: CARSON, E.W. (Ed.). The plant root and its environment. Charlottesville: Univ. Press of Virginia, 1974. p.601-642.
FURLANI, P.R.; HANNA, L.G. Avaliação da tolerância de plantas de arroz e milho ao alumínio em solução nutritiva. Revista Brasileira de Ciência do Solo, v.8, n.2, p.205-208, 1984.

HAYMAN, B.I. The theory and analysis of crosses Genetics, v.39, p.789-790, 1954.

HAYMAN, B.I. The theory and analysis of crosses. Genetics, v.45, p.155-172, 1960.

LANCE, J.C.; PEARSON, R.W. Effect of low concentrations of aluminum on growth and water nutrient uptake by cotton roots. Soil Science Society of America. Proceedings, v.33, p.95-98, 1969.

MARTINEZ, C.P. Aluminum toxicity studies in rice. Corvallis: Oregon State Univ., 1977. 113p. Ph.D. Thesis.

MATHER, F.R.S.; JINKS, F.R.S. Introdução à genética biométrica. Ribeirão Preto: Sociedade Brasileira de Genética, 1984. 242p.

OLMOS, J.I.L.; CAMARGO, M.N. Ocorrência de alumínio tóxico nos solos do Brasil, sua caracterização e distribuição. Ciência e Cultura, v.21, n.2, p.171-180, 1976. 